Sharon M. Demorest. An Exploration of the Search Behaviors of Children When Using an Online Library Catalog. A Master's Paper for the M.S. in L.S degree. November 2020. 68 pages. Advisor: Casey Rawson.

Children between the ages of 9 and 13, sometimes called "tweens," are increasingly required to be fluent in the use of technology, especially in the classroom. Often referred to as "digital natives," these children are developmentally geared toward social interaction and beginning to transfer their earlier reliance on the adults in their world to their wider peer group. This study explores the elements that influence tweens' information-seeking behaviors by examining their use of an online library catalog. Using qualitative research methods - Zoom-recorded think-aloud sessions and retrospective interviews - this study engaged a group of 10 tweens in conversations about use of the library catalog, as well as their search behaviors and search influencers in order to address the following research questions: 1) What strategies do pre-teens (children between 9 and 13) employ when using the library's online public access catalog? 2) Is there a relationship between the strategies used and any digital technology training or classwork they may have had in school or in other settings? 3) Is there a relationship between strategies used and other human influences, such as caregivers, teachers, or peers?

Results indicate that these children become information seekers at a young age - many before they can entirely remember the process - but that they do so with little direct instruction. In exploring the challenges they face - as well as their successes - this study provides insights into potential opportunities for teachers and librarians to assist children in becoming effective and discerning searchers in the library and in the broader world.

Headings:

Public Libraries

Library Services for Children

Children's Library Software

Children's Library Use Studies

Searching Behavior

Online Library Catalog Use Studies

Library Browsing

Qualitative Research 


\title{
AN EXPLORATION OF THE SEARCH BEHAVIORS OF CHILDREN WHEN USING AN ONLINE LIBRARY CATALOG
}

\author{
by
}

Sharon M. Demorest

\begin{abstract}
A Master's thesis submitted to the faculty of the School of Information and Library Science of the University of North Carolina at Chapel Hill

in partial fulfillment of the requirements for the degree of Master of Science in Library Science.
\end{abstract}

Chapel Hill, North Carolina

November 2020

Approved by

Casey Rawson 


\section{Table of Contents}

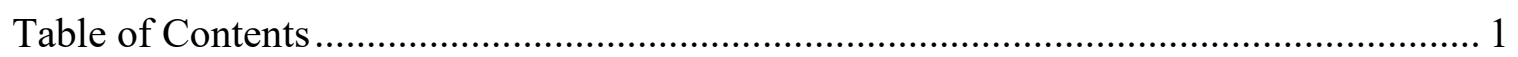

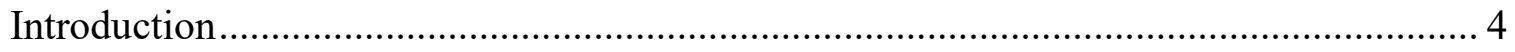

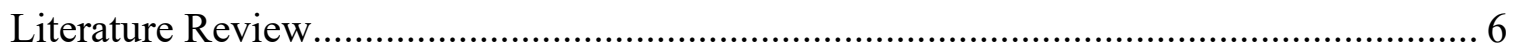

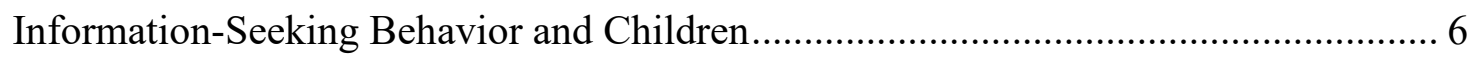

Tweens and Information Seeking …............................................................. 8

Using Technology to Search.............................................................................. 9

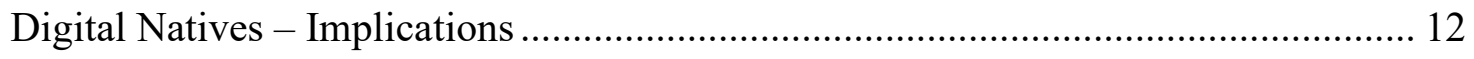

Information-Seeking Behavior in Public Libraries ................................................ 13

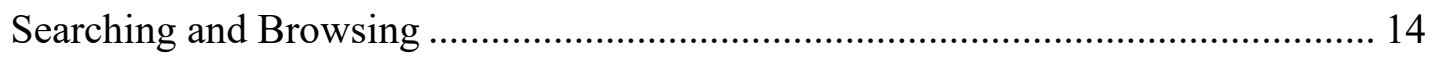

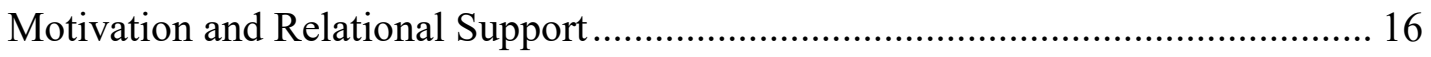

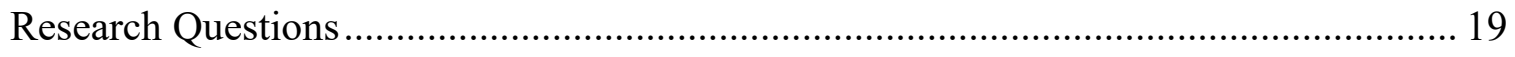

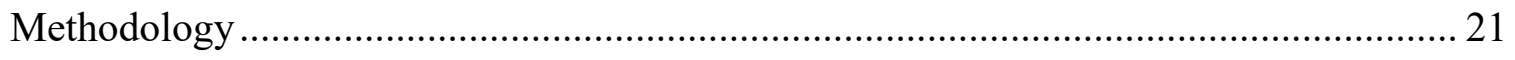

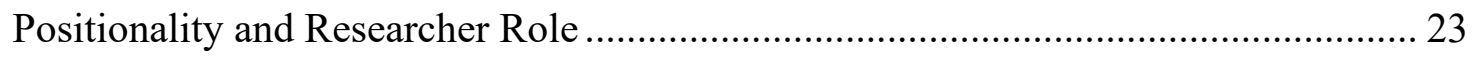

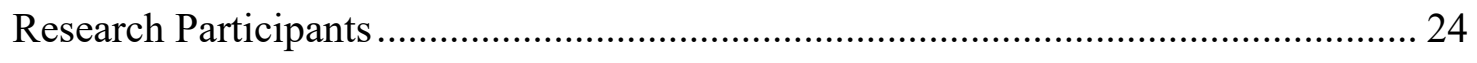

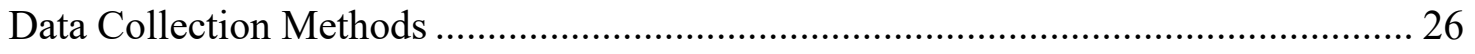

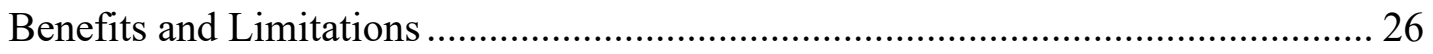

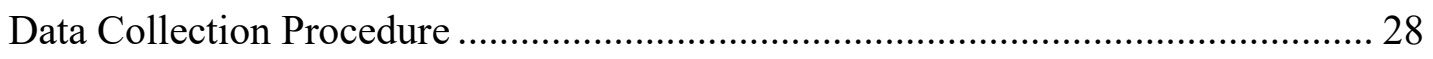




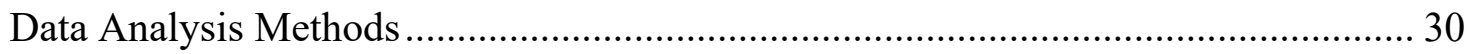

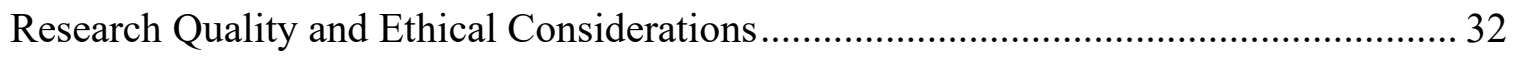

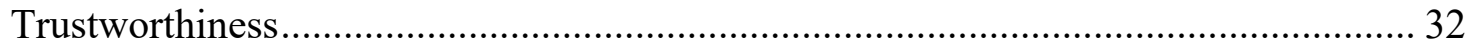

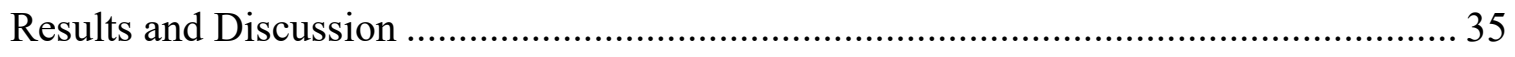

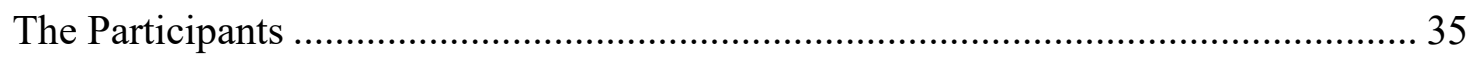

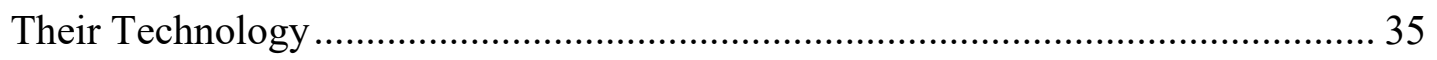

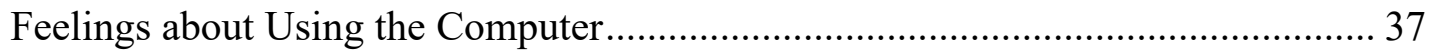

Strategies employed when using the library's online public access catalog .............. 37

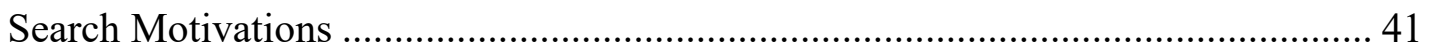

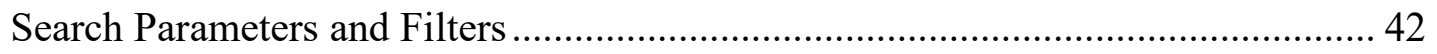

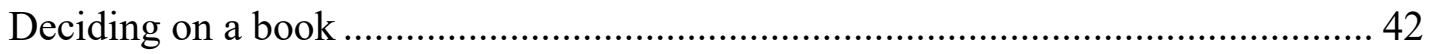

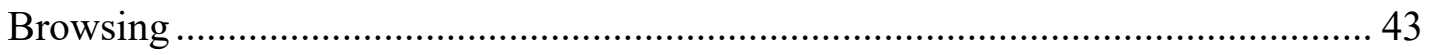

Relationship between strategies used and digital technology training or classwork .... 45

Relationship between strategies used and other human influences .......................... 49

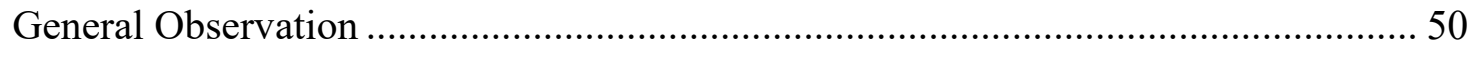

Specific Difficulties Encountered ............................................................... 51

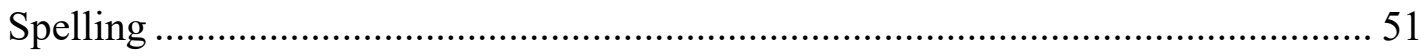

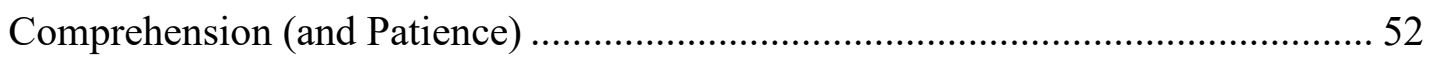

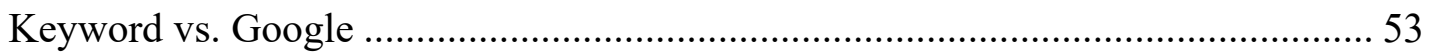

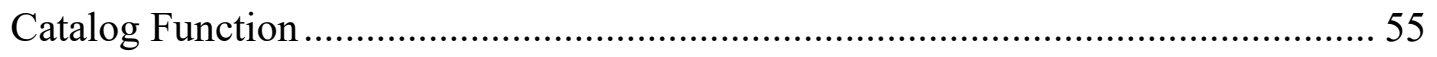




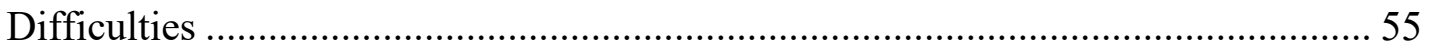

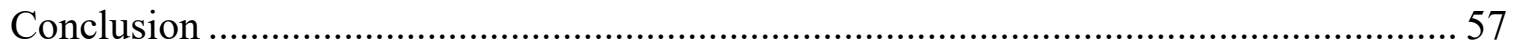

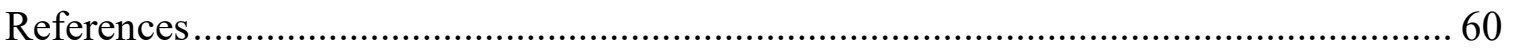

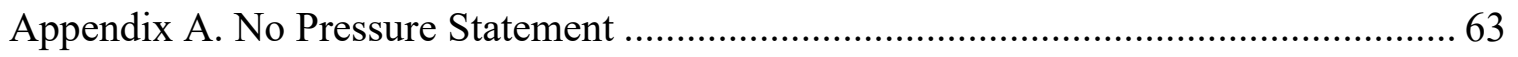

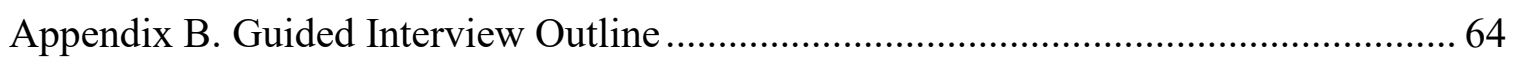




\section{Introduction}

The purpose of this study is to explore the searching and information-seeking strategies utilized by children when using online library search terminals to find books and other library materials. While previous studies have explored children's manual searching and browsing behavior in libraries and their use of technology to conduct information searches for educational projects or in their daily life - and I will refer to these for guidance - studies examining the specific behavior of children in using technology to access library resources are rare or centered on other topics. Online library catalogs are among the most basic and directed tools available for children to use in locating information. In conjunction with data gathered about the population's exposure to technology training, the results of this study provide new insights into the effectiveness of current technology education, as well as how current search tools and curriculum could be better suited to the information-seeking needs and behavior of children.

Children between the ages of 9 and 13 are understood as a population with a distinct developmental profile, and this study explores their information-seeking behavior. This group of children - sometimes referred to as "tweens" - can be characterized as exhibiting a range of behaviors such as beginning to transfer their earlier childhood reliance on adults, like caregivers and teachers, to an ever-increasing selfreliance and prominence of peer group opinions. In their schoolwork, especially, they are increasingly expected to work independently and in groups without adult input and supervision, and although many are involved in computer use literacy or programs at 
school, individual formats for this interaction with technology vary widely. As children born after the boom of technological advances that saw the rise of internet use in all phases of life, these children are among the population referred to as "digital natives" with no clear understanding of how this moniker applies to real-life behavior. Since this project was first outlined, remote classroom learning has been instituted in response to the Covid-19 Pandemic, and expectations for independent work and technological fluency have only increased. This study provides insight into how this group relates to information-seeking technology - through think-aloud observations and short retrospective interviews - specifically, their utilization of an online library catalog, one of the most basic tools in the world of public libraries to find information. 


\section{Literature Review}

\section{Information-Seeking Behavior and Children}

The term "information-seeking behavior" is accorded a broad and general definition in this study, specifically: the means by which a person searches for obtains, and uses information to satisfy their information needs (see, Vanderschantz, Hinze, \& Cunningham, 2014). It may also be referred to in this document as "search behavior." The process of information seeking has historically been considered largely a cognitive task, involving the mental processing of information needs and the results of searching to meet that need. It has been described as "essentially a problem-solving task" yet one that requires knowledge to be applied "flexibly and in concert" (Moore, 1995, p. 1).

Referencing the early work of Kuhlthau and others, Moore (1995) acknowledges the growing importance of considering the searcher's "satisfaction with the information found," as well as how the information is used, viewing information retrieval and use as a “dynamic process" (p. 4).

The Information Search Process (ISP) model created by Kuhlthau in 1999, and refined since (Kuhlthau, Heinstrom, \& Todd, 2008; Kuhlthau, 2009), is based on a longitudinal study of the information-seeking behavior of high school students over the process of a research project and was one of the first to incorporate the searcher's affect (emotions or feelings) into the analysis. More recently, Bilal (2005) has introduced the concept of the "affective paradigm," in recognition of the growing role "affective states 
play in interacting with information systems" (p. 198). While the cognitive paradigm as explored by Kuhlthau and others focuses on the totality of thoughts, feelings, and actions of the user, Bilal (2005) points out the need for more work in the study of the affect portion of that paradigm, specifically in the world of children as searchers. Noting that children have "emotional skills and needs that vary from those of adults," she concludes that they would also "need to possess not only adequate information-seeking skills but also intelligent affective strategies that will help them cope with its complexity" (p. 198). Likewise, the feelings and motivations of our group of tweens play a part in their search process (e.g., Beheshti, Cole, Abuhimed, \& Lamoureux, 2015, applying Kuhlthau's ISP model to middle-school students).

Regardless of which child development theory is adhered to, it is accepted that children have different emotional needs and abilities than adults and that these needs and abilities change over time as they move toward adulthood (Large, Nesset, \& Beheshti, 2008; Meyers, Fisher, \& Marcoux, 2009; Vanderschantz \& Hinze, 2019). Even where the process of information seeking mirrors that of adult searchers, the child's ability to navigate the same process may be markedly different (Raqi \& Zainab, 2008; Vanderschantz \& Hinze, 2019). As reported by Large et al. (2008), a review of developmental theories results in "two important consequences" for the study of children's information-seeking behavior: 1) “[I]t would be rash to apply findings gathered from adults' information-seeking behavior to their younger counterparts" and 2) "it also argues for the need to consider differently children at different ages and development levels" (p. 123-124). Thus is it important to consult for guidance literature associated with the specific age and developmental level of the children who make up the 
study group, in this case research concerning children between the ages of 9 and 13, sometimes known as "tweens."

\section{Tweens and Information Seeking}

In their study of the preteens and their everyday life information behavior, Meyers et al. (2009) describe tweens as experiencing "a period of development during which they are drawn to closer association with their peers and start to pull away from the previously comforting and secure relationships with parents and other adults" (p. 307). Idolizing the more mobile and autonomous teens, their lives involve "different information needs, strategies, and mediations" (Meyers et al., 2009, p. 307). One of their fundamental conclusions is that, for tweens - in keeping with their developmental stage - social factors play a critical role in successful information seeking and the development of the most successful information behaviors (Meyers et al., 2009, p. 337). In fact, "it is access to other people that often makes or breaks an information search as children at this age are geared toward social interaction, with caregivers or other adults or, increasingly, their peers" (Meyers et al., 2009, p. 337). In extending Vygotsky's concept of Zone of Proximal Development - suggesting that adults "play important roles in developing information-seeking skills through modeling and scaffolding behavior" - Meyers et al. (2009) found that peers are also involved in mediating tween information skills, "particularly in the realm of everyday-life information problems" (p. 337-338; (see also, Foss et al., 2012; Moore, 1995; Vanderschantz \& Hinze, 2019).

While this study focuses on use of the library catalog by individual children, the topic of caregivers, other adults, and peers came up during the retrospective interview, as well as during the think-aloud sessions, especially when discussing how search strategies 
are learned, search motivation, or how subjects proceed after a failed or problematic search. My experience as both a public library employee and a parent tells me that children at this age display a range of search behaviors and strategies, and I enjoyed exploring the extent to which the findings of Meyers et al. (2009) and others are reflected in this study. This work also takes its place among the more recent studies exploring this issue from the perspective of the children themselves, or as Meyers et al. (2009) put it, a research study done "with youth" rather than "on youth" (p. 310).

\section{Using Technology to Search}

When children use technology for information seeking, they must navigate the same process as adult users. Generally stated, they "must be able to locate, identify, collate, and organize appropriate sources to be successful information problem solvers" (Vanderschantz et al., 2014, p. 2). And despite the existence of a few web-based tools developed specifically for children, research shows that they perform no better on such child-focused tools and reach most often for resources designed for the general adult population, such as Google (Foss et al., 2012; Large et al., 2008; Vanderschantz et al., 2014). Most research to date on the information-seeking behavior of children has been in the context of directed or imposed searching for educational purposes like school assignments or projects (e.g., Madden, Ford, Miller, \& Levy, 2006; Moore, 1995; Vanderschantz et al., 2014; 2019). Searching by children outside of these imposed purposes has been studied to some extent regarding "everyday" or at-home information seeking, including use of the internet (e.g., Foss et al., 2012; Meyers et al., 2009), but I found little information on children's use of the technology designed specifically to assist in finding library resources (e.g., online catalogs). 
A number of barriers to effective information retrieval by children when engaged in searching on the internet have been exposed by the research, among which are difficulties in spelling and typing, reading comprehension, vocabulary, formulating search queries, and in evaluation of results (Foss et al., 2012; Large et al., 2008; Madden et al., 2006; Vanderschantz et al., 2014). While adult searchers also experience challenges in these areas, children's difficulties are heightened by the fact that their intellectual skills are not yet fully developed (Large et al., 2008). While the connection between age, education, and the development of spelling and reading skills can be clearly seen as connected to ease of searching - typing the search words and reading resulting resource lists - learning to formulate an efficient search query and evaluate search results is a more complex undertaking. Specifically, as recognized by Large et al. (2008), the formulation of an information need (search) in terms of keywords is not natural for adults or children, requiring a "heavier cognitive load upon the young user" due to the need to "recall" appropriate words instead of "recognizing" what shows up on the screen (p. 128).

Research on children's ability to formulate search queries, to select keywords for searching, and to process the resulting information indicates that these can be formidable challenges and not easily addressed by technology alone. As noted by Foss et al. (2012), where spelling and typing problems may be handled by software, "less obvious (to a computer) problems like the ability to formulate a query or differentiate good from bad search results remain a challenge and are unlikely to be addressed by interfaces alone" ( $p$. 559). Thus, understanding more about the process undertaken by child-users of these interfaces provides guidance "not only ... [to] search engine designers, but also ... [to] 
parents and educators" (Foss et al., 2012, p. 559). Likewise, connections gleaned by this study provide indications of where current education and literacy programs potentially are or are not assisting children in improving these skills.

In this study, children were not expected to undertake school-project-sized searches, instead looking for 1) a book they would like to read and 2) a specific resource about a topic of interest. For the second search, I solicited input from the child's parent beforehand about potential subjects of interest. In addition, from these potential subjects of interest, I attempted to find some topics that introduce specific known barriers previously identified by the research as pertinent to searching by this age group, specifically use of homonyms, spelling complications, or keyword choice. This resulted in a simplified version of the kinds of research done with children in the area of internet searching and research, and I believe that by keeping motivation high (through childdetermined search topics), the process of information seeking via the tool of an online catalog provides new insights into the way this age-group attacks the problem of meeting their information needs. By simplifying the search tool to an online library catalog, data across the group is also more easily compared and relevant themes exposed.

The focus on "motivated" searching connects this research to the research recognizing searcher affect as a part of search efficacy, above, specifically that the difference between motivated and unmotivated searchers is often the difference between success and failure. In their research on children's search roles at home, Foss et al. (2012) found that even those children classified as "nonmotivated" - "I have no interest in Google" - on the occasions that they were motivated to search online, were motived by personal interest (p. 563, 564). In addition, their research found that nonmotivated 
searchers were less aware of the features of search engines (like auto-complete or image searching), despite comparable hours of experience as determined by hours logged online on the home computer (Foss et al., 2012). Recognizing that a searcher's motivations affect search behavior (affective impact), I expected that children searching for material based on their own interests would display greater interest in the task by exhibiting better query/keyword formation and more resilient strategy adjustment. By working to connect the search tasks for this research to personal interest, I believe the study has benefited from the subjects' personal motivation to complete the tasks, thereby allowing for greater subject engagement and greater depth of data.

\section{Digital Natives - Implications}

More than one researcher has questioned use of the term "digital native" to describe this population. While admitting that these children are awash daily in Web and technology tools and effects, it has been noted that they continue to employ the tools imperfectly or sometimes not at all as they search for information (Large et al., 2008, p. 126, 132; Merga \& Roni, 2017; Meyers et al., 2009; Vanderschantz et al., 2014; 2019). Given their stage of emotional and cognitive development, they are generally less effective than adults - non digital natives - in satisfying their information needs (Large et al., 2008; Vanderschantz et al., 2014; 2019). This is not to say that they are deficient in ability, only that perhaps use of these digital tools is less a matter of being born after a particular date and more a matter of intellectual development, education, and training. In the words of Large et al. (2008), "Information seeking does not appear to be intuitive, and practice alone does not make perfect!" (p. 137). 
Labeling children digital natives has consequences, as they are then assumed to have knowledge - and perhaps are even relied upon by parents and teachers because of this presumptive knowledge (e.g., Madden et al., 2006, p. 756-757) - that must be learned to be effectively utilized. Instead of assuming a level of ability, there is an argument to be made that more efficient child-teacher interaction will result from teachers receiving better digital literacy training themselves (e.g., Vanderschantz et al., 2014, p. 2). They would then be better able to provide the support their students need to become accomplished searchers. Especially for the population of tweens - primed for social interaction and still accepting of adult intervention - this would seem to be an effective method of improving overall search effectiveness and satisfaction. Although this study does not pretend to be a thorough examination of the use of the term digital native, it provides some insights into this population's relationship with technology generally, as well as the place of digital literacy training.

\section{Information-Seeking Behavior in Public Libraries}

Raqi and Zainab (2008) have noted that "children who visit public libraries have different reasons for doing so and therefore have varied needs, be it for educational purposes or for leisure (p. 487). Most of the research on children and informationseeking behavior in libraries concerns strategies for finding books in a physical search within the library (e.g., Raqi \& Zainab, 2008; Taylor, Hora, \& Krueger, 2019), or the use of internet or library search tools in the library in furtherance of an imposed search stemming from a school-assigned project (e.g., Large et al., 2008). This study takes its place at the nexus between research on children's information-seeking behavior on the 
Internet and their in-library search behavior when looking for material for personal use, a space as yet unexplored in the literature.

\section{Searching and Browsing}

Central to the existing research on children in public libraries are examinations of their searching and browsing behavior in the physical setting of a library. While the larger number of studies concerns children searching in libraries (school and public) and their information-seeking behavior associated with school assignments, there are a few that consider children's searching for their own pleasure. It is to this body of research that we turn now.

In studies centered on children's selection of books in the library, researchers have explored the way children navigate the physical space, specifically whether by browsing or searching (Montgomery, 2014; Raqi \& Zainab, 2008), and whether the process is undertaken singly or with peers (Taylor et al., 2019, organization by genre). The research of Merga and Roni (2017) focused on search strategies by age and gender, while Shenton and Dixon (2004) centered their study on the search for non-fiction books. While these studies explore the ways in which children search for materials for their own use, none explores children's use of technology in the process. This distinction is at times a function of the study itself, as where Taylor et al. (2019) focused on search behavior in the context of the physical layout of a genre-organized library, or where the practice of shelf browsing skills are centered (Montgomery, 2014).

Yet even where search behavior is broadly considered, there is little data about the way children use search technology (online catalogs) when using the library for their own purposes, i.e., to choose a book to read. As discovered by Merga and Roni (2017), "[f]or 
the most part, children's choosing strategies showed limited evidence of learned skill and marginal use of tools such as library database catalogues and the Internet for choosing support, which was somewhat unanticipated" (p. 617, emphasis added). Where their research touched on use of online catalogs, Large et al. (2008) found that children had difficulties in keyword selection, spelling and comprehension of subject headings for use in browsing (p. 137). This underscores gaps in - and the need for further research on - our understanding of technology and its usefulness to children, as well as the very relationship children have to technology, their status as so-called digital natives.

The existing research highlights some general connections in the personal search behavior of children in libraries, specifically as to the place of browsing. Despite the lack of an exact definition of browsing, and the fact that information scientists do not agree on its place in the hierarchy of search behaviors, it continues to figure largely in the actual behavior of children in libraries. Sometimes browsing is seen as "the opposite of searching" and sometimes acknowledged and supported as a valid search endeavoreven lauded as a method of connecting children with the process of research and "cultivating lifelong, independent library users" (Coleman, 2007, p. 42-43; see also, Montgomery, 2014). Oblivious to the research and any arguments over the purpose and effectiveness of browsing, children continue to display browsing behaviors as a central method for finding a book (Merga \& Roni, 2017; Taylor et al., 2019). Regardless of where their behavior might be identified on the scale from random to what Montgomery (2014) (citing Rice, McCreadie, and Chang, 2001, p. 173) refers to as "purposive browsing," within the context of exploring the library space, children have been seen to 
use an array of strategies, including familiarity with their favorite areas of the library, use of shelf signage, exploring peer suggestions, and use of adults for assistance (Merga \& Roni, 2017; Shenton \& Dixon, 2004; Taylor et al., 2019).

Because this study restricted its subjects to the process of utilizing the online catalog, the process of browsing was similarly restricted to use of the searching and filtering tools provided by the software. Within this focus, I was able to explore the children's knowledge of these tools against the backdrop of the norm as expressed by existing research. In other words, what happens when children are not able to use the preferred method of finding a book, i.e., browsing the shelves? What form does the general process of browsing take when translated to an online library catalog?

By focusing on observing (and hearing) the search behavior of children as they search, this study makes new connections to children's perspective on the process.

\section{Motivation and Relational Support}

In her study of upper elementary children (10 years old) and information seeking, Crow (2009) has identified "intrinsic motivation" as key to creating lifelong learners and capable searchers. Among her findings - geared toward the creation of educational assignments that educate in the near- and long-term - is that both choice/autonomy and secure "anchor" relationships are key in creating strong research skills and fundamental learning (Crow, 2009, 2013). Taylor et al. (2019) note that motivation is an element of what constitutes an "engaged reader," noting that motivation "is increased when materials are relevant and students are permitted autonomy in their selection (p. 854). I have leveraged these findings by allowing the children in this study to choose 1) any book they would like to read and 2) a book on a topic chosen from subjects pre-selected to be of 
interest to them. This method provided for the best data by encouraging children to put forth their best efforts of their own volition.

In her study of relationships and intrinsic motivation for information seeking, Crow (2009) found that among students identified as displaying "dominant intrinsic motivation" information-seeking style - as determined by analysis of a self-reporting survey - one element the students had in common was "at least one information seeking 'anchor' relationship in their families" (p. 97). Since children between the ages of 9 and 13 are developmentally more open to intervention by and assistance from adults, as discussed above, it is natural that these adult relationships would be valuable in promoting sound information-seeking behavior: A "secure relational base appears to provide a needed backdrop - a distal support - for intrinsic motivation, a sense of security that makes the expression of this innate growth tendency more likely and more robust" (Deci \& Ryan, 2000, p. 235).

Given that these anchor relationship are broadly defined as "people who support[] ... [the child's] interests and information seeking behavior"' (Crow, 2009, p. 103), it makes sense that they need not always be family members but could indeed be librarians (Crow, 2009, 2013; Shenton \& Dixon, 2004, consultation with library staff as search strategy). "Library professionals are in an ideal position to observe students" (Crow, 2009, p. 103), supporting and encouraging them in their interests and helping them to make other connections (Crow, 2009, 2013). Many of the children in this study refer to instruction received from librarians or technology specialists about how to use a computer. As the skills they are learning - creating documents and projects with Google Docs - naturally relate to searching for information, library professionals are ideally 
situated to provide instruction in how this searching is best performed. These librarians are already supportive anchor relationships in the participants' lives, and these findings can be used to inform further study of particular interest to the world of Library and Information Science with potential application in both informal patron interaction and dedicated programming. 


\section{Research Questions}

Research shows that children between the ages of 9 and 13 (sometimes referred to as "tweens") occupy a special development position between adolescence and early childhood, and that some of the hallmarks of this age include their growing ability to satisfy their own information needs. In doing so, they are known to adopt a number of strategies, including reaching out to respected adults or to their peers, as well as using the technology that is available to them, usually internet sources (the Web). In addition, it is expected that the information-seeking efforts of this defined group of children, like other populations, is likely to be influenced by affective elements such as motivation and prior experience. In this study, information seeking is broadly defined as the means by which a person searches for, obtains and uses information to satisfy their information needs, and I have examined specifically those information-seeking behaviors utilized by the subject group in finding materials via the online public catalog in use at the local library.

This study examined the information-seeking behavior of children in the public library, with a focus on the following research questions:

1) What strategies do pre-teens (children between 9 and 13) employ when using the library's online public access catalog?

2) Is there a relationship between the strategies used and any digital technology training or classwork they may have had in school or in other settings? 
3) Is there a relationship between strategies used and other human influences, such as caregivers, teachers, or peers?

This focused examination - by think-aloud sessions, retrospective interviews and thematic analysis - offers a better understanding of how this population searches for and finds information, how they react to available technology through attendant strategies, as well as what influences have been involved in the development of their searching skills. In doing so, this study provides insights into the advisability of applying the term "digital native" to any population. 


\section{Methodology}

The methods undertaken in this exploratory study conformed to the highest standard of qualitative methods, including observation of the children as they performed their chosen searches, by which means I hoped to uncover unanticipated phenomena (Lockyer, 2008). During search sessions, I was present as a participant-observer but only to the extent necessary to maintain the think-aloud process, while during retrospective interviews I was present as the interviewer. Due to precautions imperative during the ongoing Covid-19 Pandemic, all contact was via Zoom meeting - including screen-share technology -- so I was never physically present with any child. I have taken every precaution against influencing subject behavior and taken due note of my own perspective and biases. By being clear about my position and methods taken to account for it, I have maintained the integrity of the qualitative process, which acknowledges that absolute objectivity is impossible (Lockyer, 2008).

Data collected - in the form of transcribed think-aloud sessions and guided retrospective interviews - was likewise analyzed according to the qualitative method of thematic analysis. Specifically, data was gathered through think-aloud sessions via Zoom with children between the ages of 9 and 13 years old, with children sharing their screens with me for all searches. Sessions were recorded and transcribed, and I took contemporaneous notes, as well. Transcription was reviewed against recorded Zoom video at least one time for each subject in order to connect transcribed material with cursor movement and search choices, connecting words with actions. In addition, I 
referred to the recorded videos as necessary to add to my understanding of verbal responses. A short, guided reflective interview was conducted after each session to solicit any additional information the child wanted to contribute about the process, as well as to explore each subject's comfort level with technology and previous technology exposure and training. The same recording, transcribing and note-taking procedures were undertaken with the interviews as with the think-aloud sessions, including reference to video recordings for clarity. I performed a thematic analysis on all transcribed documents, using an iterative and comparative process to elicit potential themes and connections among the data. Analysis was undertaken through an inductive approach in order to "build themes" from the existing data with the goal of exploring the search behavior exhibited by the subject children (Allen, 2017, p. 1758).

The exploratory nature of this study, and the special responsibilities when conducting research involving children, are both considerations that drove the methods undertaken. Because I hoped to gain new information (or to add to existing information) about the nature of children's engagement with library search tools, it made sense to go to children in libraries in order to capture the complexities of that behavior. By engaging directly with the experiences of children - hearing directly from them - about their thought processes while engaged in using library search tools, I believe these results provide insights into the subject behavior, as well as potential guidance for performing additional studies in the future. This type of exploration is uniquely suited to the tools and methods of qualitative research.

One note about carrying out this study during the current pandemic. The adjustment to performing this research via Zoom only made sense, allowing all parties to 
stay safe while taking advantage of the opportunity to have sessions automatically recorded through Zoom technology. In fact, I believe this method actually provided me with more data than could be entirely analyzed under the time constraints imposed by program deadlines. Although there were occasional technology breakdowns, such as loss of connection or interference that garbled responses - with parents sometimes stepping in to push buttons or otherwise assist - it provided an up-close view of how young students deal with remote school and remote life. Having a recording of every link clicked and every area moused or hovered over allowed me to see more closely how participants navigated through their search and was an unanticipated benefit of being forced into this method. No amount of notetaking could encompass the totality of this information, nor did participants' verbal responses reflect the bulk of their onscreen movements. If I were to do this study again, I would consider less notetaking and more focus on following up and exploring the specifics of participants' on-screen movements.

\section{Positionality and Researcher Role}

I was the only party involved in conducting both the think-aloud sessions and the reflective interviews with the subjects, as well as transcribing the think-aloud sessions and interviews and performing the thematic analysis of those documents. Where I had questions of process, I consulted my advisor for guidance and adjusted accordingly. For instance, due to shortness of time, I fully transcribed only the first three sessions, while the remaining seven were fully transcribed only as to the substantive think-aloud and interview sections. Introductory material - including consent and assent procedures and 
reading the No Pressure Statement, attached as Appendix A - was substantially the same for each session and was reviewed but not fully transcribed.

I have worked with children and books for over 10 years, in retail and in school and public library settings, and am currently employed in the youth and family section of a large public library. Because I have been interested in this topic for years and have formed some of my own theories, I needed to keep an open mind toward potential findings. In addition, I have a parental lens since I have three children myself. Although my own children are all out of the subject range of 9-13 years old, I know that my experience as a parent does guide my interaction with and overall view of children. My positionality toward this topic is potentially an asset, allowing me insights into the subject. Where there may be the danger of my own beliefs or expectations getting ahead of actual results, I have relied on sound methods - including a clear record of all interactions and analysis - and input from my advisor to preserve the validity of the findings.

\section{Research Participants}

While any population of children using library search terminals is, in a sense, "self-selected" - children who are, at a minimum, willing to engage with the technology - it is not a hindrance to the validity of this study to consider only that population, as the current research explores "how" children engage with the technology, rather than "why" they may not engage. By definition, "children using library search tools to search" are the population of interest to these research queries. A study of why children do not engage with library search tools would surely be of interest but was not feasible given the available time and resources. By the same token, while it would be of interest to study 
children at multiple libraries or library branches in order to create a broad sampling of the population of children using library search tools, the restricted circumstances of this study required acknowledging that that study must wait for a future effort. Increasing our understanding of the manner in which children engage with library search tools, as well as any hints as to what influences may cause them to engage successfully, is certain to add to current knowledge. In recognition of the needs of this specific study, including time constraints, it served legitimate research goals to seek a purposive sample of children by snowball sampling methods (Lockyer, 2008, p. 816)

Because working with children directly can be a sensitive matter - involving both the needs of individual children and the justified concerns of their parents - I began by reaching out to personal contacts among library coworkers and fellow students at UNC, hoping to grow a sample of 10 to 15 children within the target age range of 9 to 13 years. By this method, I was able to gather a sample of 10 children. Six boys and four girls were part of the study, and ages ranged from 9 to 13 , covering grades from third to seventh, although there were no fifth-grade participants. In addition, six of the participants attend the same school, and three of these were siblings.

In order to offer my young participants a reward for taking part in this study, I applied for and received a Carnegie Grant in the amount of $\$ 150$ to cover the purchase of 15 Target gift cards in the amount of $\$ 10$ each. Since I only had 10 participants, I returned the remaining $\$ 50$ to UNC. Another unanticipated positive effect of modifying the study to be carried out remotely by Zoom meeting was the elimination of all potential travel expenses for both me and study participants. 
I applied for and obtained IRB approval, and all relevant guidelines were followed for the safety and security of all participants. Although subject children were chosen by a snowball sampling method this time, later studies could be expanded to include a broader and more systematic sampling of children and libraries. Methods used in this initial study may help guide the planning and structure of those later projects, while insights gained provide a foundation for the creation of tools or training that, in turn, will lead to generations of children who are successful searchers, both in the library and in the wider world of children's searching and information seeking.

\section{Data Collection Methods}

As noted above, I used a set of children chosen by snowball sampling techniques, beginning among my library coworkers and fellow students in the SILS program at UNCChapel Hill. From initial personal connections, I was able "snowball" the sample to other subject children by use of techniques such as email and word of mouth. In the end, I was able to gather 10 children who (with parental permission) were able to participate in both the think-aloud session and the follow-up reflective interview. Use of snowball sampling techniques made sense in this case because this study is exploratory in nature, and I was specifically looking for insights to build on from the data (Lockyer, 2008).

\section{Benefits and Limitations}

This study explored what happens inside a child's mind as they choose (and reject and create) strategies they will utilize in searching the library's online catalog for materials. This study contributes to our knowledge of those strategies, cognitive and affective, acknowledged to be unique in children as a specialized population (e.g., Bilal, 2005). Data taken from transcriptions of think-aloud sessions and reflective interviews 
allow access to that information in the most meaningful way possible: through their own words. Thematic analysis, considered in conjunction with contemporaneous notes and video recordings, allowed me to identify themes and make connections between their thoughts and actions, and this data was enriched by content from the follow-up reflective interviews. Similar to the research goal stated by Foss et al. (2012), I aimed to "arrive at a broader understanding of the whole searcher by observing affect, uncovering searching rules, and noting the people who influence search" (p. 558), in this case within the world of online library catalog searching. Taken together, the data from think-aloud sessions and interviews - especially with the added information from recorded screen-share sessions via Zoom - provided the overwhelming benefit of allowing me to explore the process up close and to gain the rich insights that will fuel further research. Specifically, this raw data also provided context to the final results, as I have been able to include relevant quotes to enhance understanding of subjects' personal experience. Use of think-aloud sessions and interviews - although not entirely overlapping in substance - along with my observational notes and recorded evidence of subjects' on-screen movements, also functions as a system of triangulation to increase the trustworthiness of the results (e.g., Meyers et al., 2009).

The natural limitation of such individualized analysis is that the results of this study are not generalizable to other populations. Nor are they meant to be. As a function of the qualitative and exploratory nature of this inquiry, these results will apply specifically only to this limited group of participants. The methods used, however, may be useful in further, broader inquiries, while these findings may serve as stepping-stones to additional explorations or potential quantitative experiments. As it has been 
recognized that children face numerous barriers to searching as befits their cognitive and affective situation (e.g., Foss et al., 2012 and discussion therein), this study provides more focused insights by narrowing the search parameters. Instead of attempting to perform the broad internet searches for school research projects - including age-related difficulties with search query creation - searching the online library catalog focused more on specific difficulties with using a designed tool, including typing/spelling, use/understanding of library specific information, and filtering results, while still allowing for an examination of the general strategies employed by young searchers. It also provides a glimpse into the effect of a Google-style searching on use of other search tools, since Google was the predominant tool used by this group of children.

This sampling method cannot claim to produce a sample representative of the entire world of children using library search tools. Although a broader sample of the community would provide different experiential data, this sample nonetheless gets at the heart of the research questions, being composed of the very population I hoped to access. While not representative of the entire world of children using search terminals, this population has provided insights and allowed me to begin to make connections between children's search strategies and other influences, such as technology training, which is valuable as new information in the field.

\section{Data Collection Procedure}

Data was collected from the sample population according to the procedural elements set forth below:

1. Sessions were held using the BiblioCommons online catalog utilized by the Chapel Hill Public Library. 
2. Think-aloud sessions (with follow-up retrospective interviews) to be held by Zoom meeting employing screen-share technology were scheduled with individual children, in conjunction with parents.

3. "No Pressure" Statement (Appendix A) was read to each participant at the beginning of their think-aloud sessions.

4. Children were asked to find two things during their think-aloud session:

a. A book they had never read before that they would like to read (their choice).

b. A resource about a specific topic, which I assigned. Although this was an imposed search, I solicited input from parents during the recruitment process about potential topics of interest to increase personal or intrinsic motivation (Crow, 2009; Madden et al., 2006), while simultaneously hoping to provoke some known challenges for this group, especially involving spelling and comprehension. Altogether, the participants searched for Ancient Egypt, whales, meerkats, Muhammad Ali, tsunamis, cartooning, leopards, and lightning.

5. Directly following each session, I conducted a short, retrospective interview of each child regarding the following elements:

a. Background data (age, grade, school, etc.)

b. Feelings about using computers and search tools, in general

c. Feelings about this particular search tool or process

d. Technology courses or training they may have undergone

e. Other individuals/situations affecting search behavior 
6. Retrospective interviews followed the substance of the Guided Interview Outline attached as Appendix B.

7. Sessions were recorded (audio and video via Zoom), and I took notes of my observations during each session.

8. Think-aloud sessions and interviews were transcribed completely to the best of my ability, although introductory and non-substantive portions were not entirely transcribed due to time constraints.

9. Thematic analysis was performed on all transcribed documents.

10. All transcribed documents were reviewed in conjunction with video recordings at least once for additional data collection and thereafter as relevant.

11. Themes were collected.

12. Comparative thematic analysis was performed, connecting themes across the sample.

\section{Data Analysis Methods}

For this study, I used a process of thematic analysis in reviewing all transcribed materials. This is an iterative process beginning with an initial scan of a transcription, review generally for overall understanding. I made an initial scan of a subset of all materials - and a comparative review of transcribed materials with screen-share videos before beginning to attribute themes or relevance (data points) to the raw data. I then completed this two-fold process - transcriptions with screen-share video - scanning through the remainder of the documents, reviewing the same subset and beginning to note relevant themes and data points. As connections and repeated elements begin to emerge, I began creating a rough coding frame based on these connections and repetitions. 
Continuing the process of scanning, reviewing and comparing, I then returned to these same documents a third time and attempted a rough sorting of the text according to this fledging coding frame.

While undertaking the process of scanning, reviewing, and coding throughout the data, I continued to add and reorganize my coding frame, often working back and forth between transcriptions for comparison and clarity. During this process, I also removed some themes that appeared less relevant. At times, I also re-reviewed portions of the video for greater understanding and to add to the data. When all documents had been through the entire process, I reviewed my frame and returned to the original documents and video data for final comparisons and connections.

At key points during this process I touched base with my advisor to ask her opinion on my process and analysis to that point and to implement any changes she suggested.

Analysis was by qualitative thematic analysis. Because the interview encompassed my attempt to gather specific types of information, e.g. technology classes the child may have taken and other people who may have influenced them, these responses were somewhat restricted. Nonetheless, I also asked numerous open-ended questions and followed up on themes introduced by participants, and I performed the same analysis on these interactions. When all possible themes were identified, I utilized qualitative comparative analysis to arrive at results suitable for discussion and reporting in tabular and narrative form, drawing out illustrative quotes from participants where appropriate. 


\section{Research Quality and Ethical Considerations}

Both the think-aloud sessions and the reflective interviews involved my interaction with the subjects. To avoid inserting my own opinions in this process, and to maintain the highest levels of credibility and dependability throughout this study, I practiced neutral check-in questions for the think-aloud process and utilize a guided interview format for the reflective interviews. I prepared a "No Pressure Statement" (Appendix A) and presented it verbally to each child in order to make clear that there is not pressure on them to give any particular answer, that I am interested in whatever they are thinking, and that there is no pressure to continue if they feel uncomfortable at any point in the process. I did this in order to reassure the subjects - as well as reminding myself - that there is no judgment involved in my presence during the process or in any questions I asked. Where appropriate during the sessions, I reiterated the substance of this statement, reminding participants that whatever they said was a good answer and that every answer was helping me with my study. Utilizing these techniques, I believe that the methods used and the conclusions arrived at from this study are transferable to other suitable populations and further research.

\section{Trustworthiness}

I maintained complete records of my process through a handwritten journal and online documentary records, including changes to data collection tools and methods used, and I have been transparent about my positionality and the barriers I encountered. Where 
appropriate, I encouraged input from peers and my advisor. In all aspects of this project, I have been in communication with my advisor so that any potential problems could be resolved. I have a strong interest and background in the subject matter of this study, and I believe that my insights are beneficial to consideration of this problem. To the extent that I may have had opinions about an outcome, I maintained awareness of them and worked to question my own assumptions. I also enlisted the assistance of colleagues and my advisor to review my work and assumptions.

This study posed no threat to participants. I maintained confidentiality as to participant identity and followed all procedures and best practices as required by IRB guidelines. I will not be maintaining any personal or identifying information of the subjects, and the study did not explore sensitive or personal areas.

For this study, I was especially careful to ensure that the children who participated in the think-aloud and follow-up retrospective interviews were free to express their own feelings and thoughts about the process, as well as about their information-seeking behavior in general. Because this was an exploratory study utilizing qualitative research methods, it was essential that each subject child be comfortable with me as the observerquestioner and did not feel that I had any expectations about how they should or should not behave or answer. Subjects were reminded that there were no right or wrong answers and that they had the right to stop at any time. Toward that end, I read the No Pressure Statement (attached as Appendix A) to each child, sticking as closely to the written words as is possible. No child asked any questions about the statement or expressed any concerns about answering. I understand that this does not mean that the children in fact did not feel any pressure, and where I believed I saw these effects, I acted accordingly, 
e.g., by reassuring them that they were doing great or by terminating difficult searches. Despite my best efforts, I believe there were times when the participants tried go too fast or to cover up what they perceived to be wrong choices or bad search techniques because I was watching them. Sometimes these moments provided an opportunity for further learning, and I could encourage the searcher to slow down or back up and tell me their thoughts. Sometimes, however, I chose not to follow up, deciding that relieving participant stress was more important than my need to understand. 


\section{Results and Discussion}

\section{The Participants}

The group of tweens that agreed to be part of this study included children from 9

to 13 years old, with five 11 -year-olds $\left(6^{\text {th }}\right.$ grade), two 9-year-olds ( $3^{\text {rd }}$ and $4^{\text {th }}$ grade), and one each at age 10 ( $4^{\text {th }}$ grade), 12 ( $7^{\text {th }}$ grade), and 13 years old $\left(7^{\text {th }}\right.$ grade). There was no child from the fifth grade, but six of the participants attended the same school, and three were siblings. In addition, there were six male and four female participants. See Table 1, below. Given the nature of the study and their agreement to participate, it is not surprising that all of them appeared to be interested readers.

Their Technology

Five of the children I talked with reported that they have their own computer, and that they keep their computer in their room. A sixth reported having a personal computer but said that they are "not allowed to have any electronics besides ... a radio" in their bedroom [R4]. An additional three initially answered "yes" when asked if they had their own computer, but further questioning showed that they were referring to the Chromebook they had been given by the school for remote learning during the pandemic. This was often a surprising difficult issue to resolve, as children routinely referred to the school laptop as "my own computer" - especially when they did not have another computer to call their own - occasionally requiring some legalistic wrangling to reach a 
conclusion: "Well, this is technically the school's computer. But it has my name on it and only I use it" (R6, 345).

Table 1. Demographics

\begin{tabular}{|c|c|c|c|c|c|c|}
\hline Identifier & Age & Gender & Grade & $\begin{array}{c}\text { Own } \\
\text { Phone }\end{array}$ & $\begin{array}{c}\text { Own } \\
\text { Computer }\end{array}$ & $\begin{array}{c}\text { Computer Games } \\
\text { Online }\end{array}$ \\
\hline R1 & M & 9 & 4 th & N & Y & N \\
\hline R2 & F & 11 & 6 th & N & Y & N \\
\hline R3 & F & 11 & 6 th & N & Y & N \\
\hline R4 & F & 12 & 6 th & Y & Y & Briefly \\
\hline R5 & M & 11 & $6^{\text {th }}$ & Y & N & Y \\
\hline R6 & M & 11 & $6^{\text {th }}$ & N & N & N \\
\hline R7 & F & 11 & $6^{\text {th }}$ & Y & Y & Y \\
\hline R8 & F & 9 & $3^{\text {rd }}$ & N & N & N \\
\hline R9 & M & 10 & $4^{\text {th }}$ & N & N & Y \\
\hline R10 & M & 13 & $7^{\text {th }}$ & Y & Y & Y \\
\hline
\end{tabular}

Only three of the participants have their own cellphone, but most of them have used a parent or grandparent's phone either to search or to play games. When using a smartphone to search, they reported that they did so because it was faster or more convenient - not requiring powering up, logging in or "walking upstairs" (R3, R5, R10) while an equal number specifically preferred searching on a computer to using a phone because phones are tiny and hard to type on and because "more things fit" on the computer screen (R2, R3, R7). One phone searcher preferred to use their phone because, in addition to being faster and more convenient, it allowed him to avoid the school surveillance installed on his school laptop, which will "message all the teachers that you're looking up pictures of tigers when you should have been looking up pictures of circuit boards" (R5, 654-656).

While a few participants used the computer for online gaming, the majority reported either not being allowed to play online video games on the computer, playing 
only by themselves online, allowed to play only "learning games," or mainly using another platform like Nintendo Switch or Xbox for gaming. Only three reported playing some online video games, with or without friends (R5, R7, R10), and three reported playing games on smartphones either alone or together in person with friends (R4, R5, R8).

\section{Feelings about Using the Computer}

The feelings expressed by these searchers when asked how they feel about using computers are partially captured in Table 2 , below. For the most part, they all said that they liked using the computer, and most said they felt like they were good at finding what they need when using one. But some were careful to point out that they have other interests, too, like R1 who said, "I like to use them, but they're not, like, my favorite thing inside the whole entire universe" (339-340), and R9, who was very specific about choosing to hand-write his stories: "I write "em personal" (397). "I mean, what if the computer shut down and never woke up, or we had to get a new one? I just do it on a piece of paper ... so I can share it with the family" (R9, 408-411).

\section{Strategies employed when using the library's online public access catalog}

When asked to search for a book to read for pleasure (Search Task \#1), eight out of 10 study participants looked for a fiction book. Of these, seven searched for a specific book, including two who searched for a book they had already read. Of the five participants who searched for a book they had not read before, two looked for books that had been recommended to them, while three were looking for a new book in a series they follow. 
Table 2. Using the Computer

\begin{tabular}{|c|c|c|c|}
\hline Participant & About Using Computers & Early Computer Memories & $\begin{array}{l}\text { Searching at } \\
\text { Home }\end{array}$ \\
\hline R1 & Like to use it; fun & & At-home projects \\
\hline $\mathbf{R 2}$ & $\begin{array}{l}\text { Liked being able to learn } \\
\text { how to type }\end{array}$ & $\begin{array}{l}\text { Photos as babies with Dad } \\
\text { while he uses computer; used } \\
\text { computer in Kindergarten for } \\
\text { schoolwork; using computer } \\
\text { for a long time }\end{array}$ & $\begin{array}{l}\text { Follow up on } \\
\text { questions, } \\
\text { sometimes from } \\
\text { books }\end{array}$ \\
\hline $\mathbf{R 3}$ & $\begin{array}{l}\text { Fun to type fast, really, } \\
\text { really fast; pretty } \\
\text { comfortable }\end{array}$ & $\begin{array}{l}\text { Picked up stuff when "little" } \\
\text { being around parents using } \\
\text { computers }\end{array}$ & $\begin{array}{l}\text { Find information, } \\
\text { like cat names } \\
\text { and weather }\end{array}$ \\
\hline R4 & $\begin{array}{l}\text { I'm pretty good with } \\
\text { computers }\end{array}$ & & $\begin{array}{l}\text { Boredom; craft } \\
\text { ideas }\end{array}$ \\
\hline R5 & $\begin{array}{l}\text { Like to use it; I've used } \\
\text { computers a lot }\end{array}$ & $\begin{array}{l}\text { Taught to use online catalog } \\
\text { by Mom "a lot of years ago" }\end{array}$ & Find information \\
\hline R6 & $\begin{array}{l}\text { I like to use it. It's really } \\
\text { useful }\end{array}$ & & Rarely \\
\hline $\mathbf{R} 7$ & $\begin{array}{l}\text { Fun to use; easier to type } \\
\text { than to write }\end{array}$ & $\begin{array}{l}\text { Haven't used Firefox since 1st } \\
\text { grade }\end{array}$ & Online shopping \\
\hline R8 & A little bit easy & & Look up dogs \\
\hline R9 & $\begin{array}{l}\text { Comfortable; always find } \\
\text { the answer }\end{array}$ & Pretend typing at 2 years old & $\begin{array}{l}\text { Information; } \\
\text { confirm things } \\
\text { learned IRL }\end{array}$ \\
\hline R10 & $\begin{array}{l}\text { Very helpful; I can usually } \\
\text { find what I need pretty fast; } \\
\text { helps to make things look } \\
\text { good }\end{array}$ & Computer lab in Kindergarten & $\begin{array}{l}\text { Information, like } \\
\text { to confirm book } \\
\text { and movie plots }\end{array}$ \\
\hline
\end{tabular}

Two fiction searchers attempted to access staff-created lists on the catalog, specifically because they know that their mom makes lists for the library. One of these searchers (R2) successfully navigated to the landing page for library lists but then entered the title of a book recommended to them by a friend as a keyword search, without ever accessing any lists. They later said that they sometimes use the catalog to "look at lists" because they knew their mom "makes a lot of lists of books we should read, and sometimes she puts them here," but then frankly admitted, "I don't know how to get there from here" (R2, 207-208). Participant R3 also began by navigating to the lists page of the catalog because "my mom would probably have put something on here" (40). They 
selected a "Best Books of 2019" list, which they looked through, eventually selecting a title they were "supposed to read." These sibling searchers were aware that lists can be used to find new books and claimed to have used the lists before, mainly because their mom makes lists for the library, but when I asked R3 if they could tell who had made each of the lists, they admitted that they could not. Even when they remembered the name of a list their mom had made, they were unable to find the specific list to browse. No other searchers referenced library lists. In addition, only R1 searched the title of a book using the title search parameter; all other searchers used only the keyword function to perform their initial book search.

When asked to find another book that was "like" one they had enjoyed - an onthe-fly attempt to produce a search that is closer to browsing and uses more specific catalog tools - these searchers employed a variety of techniques, including: searching for a favorite author by name to find more books they wrote, using keywords, browsing their own book history for new ideas (R4), and searching the title of a favorite book to see if "something might come up" (R1). This last suggestion was from a younger searcher who remembered previously searching for the Spy School series and finding other fiction featuring spy schools. Searching The Penderwicks, however, did not bring any useful results. Nonetheless, I found this to be an interesting example of a searcher scaffolding their own learning on prior experience, and the same type of self-referential learning was seen when R3 tried to reason out a series connection between book titles based on her experience of the naming of series books, and when R5 discovered new layers of filters during a search. 
Searchers who attempted actual keyword searches, such as "magic" for books like Harry Potter or Fablehaven seemed not to have a plan for dealing with the resulting large list, even where they were familiar with using the filters. One searcher (R4) said she would just "look through here at some stuff" (66), while R3 changed tactic to look for a "Books Like Harry Potter" list. Once again, however, the specific list remained elusive. Some searchers $(\mathrm{R} 7, \mathrm{R} 9)$ began with Google-style search phrases that required significant re-structuring to provide quality (or any) search results (see below at "Keyword vs. Google"), while R6 tried to search for "juvenile fiction" but gave up when they could not spell "juvenile." Searcher R2 admitted that, while they do search for specific books on the catalog, if they want something about a topic, they just "ask my mom [library staff] to get one about the topic for me" (R2, 185-187).

Because Search \#2 focused on searching an assigned topic, keyword searching was more effective and used by every participant. While not without its challenges, especially spelling and comprehension, the participants by and large simply entered the term they were assigned and proceeded to look at the list, filtering as required and as the searcher was able. Because the searchers had less need to be "interested" in the book, they were free to look at a few and tell me how they would decide whether or not to get the book. For instance, they all knew the book should be factual, and they proceeded to compare books by the various available information (see "Deciding on a Book," below) but especially by looking for substance and answers to specific questions. Although a few participants never filtered the list and appeared unaware of the function, most began by filtering (e.g., genre: nonfiction), and some (R6, R10) caught on as they explored the page, applying knowledge from using other online catalogs. As R10 described it, 
[I]t's pretty easy to catch on, just looking around ... [U]sually on the side, that's where, like, you can choose book or eBook and stuff. So, I just use my previous knowledge of other sites, and usually they're pretty similar. So, I can catch on pretty easily (230-234).

Motivated to search and armed with prior experience, many of these searchers showed themselves quick to pick up on at least some of the specific tools during the search tasks.

\section{Search Motivations}

Participants who previously had used this or another library catalog reported doing so mainly to look up a specific book to see if it's available to check out or to find where it is located in the library during a visit. They reported searching for potential new books by favorite authors or in series that they are already reading, using keyword searching almost exclusively. Several reported heavy use of the NCDigital site to download audiobooks or eBooks during the quarantine lockdown, and at least one (R4) has continued to download eBooks for reading because of ongoing limitations on using the physical library. Most searchers were familiar with the process of putting a book on hold, and many ended their search for a book by saying they would "place a hold," hovering their cursor over the language on the library button. Children of library staff unanimously referenced putting books on hold for parents to pick up when at work. Even R9 - who reported never having used this or any other library catalog and who thanked me for showing them "another website ... [to] look for books on" $(\mathrm{R} 9,194)$ - said they would place a hold so "the next time my mom will go to the library, it would be there waiting for me" (R9, 196). Sadly, this eager searcher misunderstood the availability information for the item, so if they had placed the hold, they would actually be waiting for the book, rather than the other way around. 


\section{Search Parameters and Filters}

Although one of the youngest searchers (R1) routinely set parameters for "author" or "title" when searching, use of this function was spotty at best among other participants. Most searchers, including R8, who appeared hesitant to click on anything, clicked the link embedded in the author's name for more by that author. Searcher R3 also made a specific author search, and once selected "tags," a catalog-specific method for accessing books thematically. When asked why they did so, however, they said they were "just looking to see if there was anything else and accidentally clicked on tag. Not sure what tag means ..." (R3, 159). Occasional other searchers, like R4, also briefly investigated the search parameter options, but the vast majority of searching took place as keyword searches with no attempt to begin with a more specific focus.

The three youngest participants, R1, R8, R9, all of whom are from different schools and already doing school projects online, were the least likely to use catalog result filters, e.g., genre, audience, format. Searcher R1 was familiar with this catalog, R8 was reported to have used a different library catalog to search, and R9 had never used the catalog and had no school library but was devoted to searching on Google. In the course of their search tasks, none of these participants voluntarily filtered their search results, and when I suggested that R8 try the function and then go back to the full list, they did not know how to "unclick" the filter.

Deciding on a book

When deciding on a book, the participants were most likely to consider the description/summary (8) and images of the front cover (5) in order to decide if it was a book they wanted. They also considered any available comments or ratings, although 
some also balanced those with publishing data, reasoning that newer books might not have had time to get reviews (R2, R5). They also considered the title for its substance (R5, R6, R10) and for names known for providing factual information, like National Geographic or Eyewitness (R3). Also considered were availability and previews/samples.

Images of book covers were important in catching the searcher's eye ("looks cool," R9) and matching a recollection of a book seen elsewhere (R10). Searcher R7 even spent considerable time trying to determine series order by squinting at the book images and trying to find the information on the thumbnail image. They were persistent in this task for a surprisingly long time, although they never attempted a search by series, nor did they click on any particular book, which would provide that information. Instead, they suddenly switched to a new page and Googled it!

Given that research shows that children select physical books much the way adults do - by looking at covers, liner notes, etc. - it was not surprising that they would attempt the same process when selecting books online. In fact, multiple searchers described the way they would get a book from the library, first looking at the title, back and front inside flaps (R5, R6), and even "reading a chapter or two" (R5), none of which is truly possible with the online catalog. In fact, when trying to decide between books, even very proficient searchers found themselves stumped by missing images and information: "[I]t has no cover or description, so I'm not quite sure about it" (R10, 163). Browsing

Although not technically the subject of this study, this group of tweens was quick to note the differences between using an online catalog and being physically in the 
library. Nearly all of them (9) were clear that they don't randomly search on the library catalog, instead using it only when they have a specific book, series, or author in mind, or if they want to see if a book is available to check out. Otherwise, they prefer to browse, go to their favorite sections, or just "browse all the books" (R4). Some told stories of having to revert to using the catalog at school when the library was rearranged:

When they rearranged the library, I also had to [use the catalog]....After I had finally completely understood everything in the library, they completely rearranged everything! (R5, 504-512).

One searcher said they liked to use the catalog in their elementary school - including large buttons for genre searching - but their middle school is so small that a catalog is unnecessary (R10).

Covid-19 was also on the mind of these dedicated browsers, with R4 stating that they would rather get the physical book but have been utilizing audio or eBooks because that is the only option right now.

If I'm in the library ... surrounded by all the books, I kind of just want to pick it up and do it. But I love to read, so I'll just get the one that's most available to me that I can read, like that second (136-138).

Similarly, searcher R6 found the catalog to be "a lot more useful when it's virtual like this, ... when you're, like, not allowed to browse the shelves" (396-400). Nonetheless, they declared passionately, "when I go back to libraries - no matter which one it is - I think I'm just going to ... just browse the shelves" (401-404).

In keeping with prior research by Merga and Roni (2017) and Taylor et al. (2019), these tweens would prefer to be picking out books in the physical library. Sadly, except for R10's description of the big genre buttons on their elementary school library catalog, 
even those searchers who are most comfortable with the catalog use it more as a finding aid than a true tool for browsing and finding new book ideas.

\section{Relationship between strategies used and digital technology training or classwork}

It must be noted that questioning the participants about their computer- and search-related education was not a straightforward matter. Many said they had taken computer or technology classes, which overwhelmingly involve learning "keyboarding"notably, a term often used by the participants themselves - and how to perform office and school functions like writing a professional email to your teacher and using Google Classroom for document preparation and slide presentations. One participant said they had a technology class, which they then described as "learning all about North Carolina" and math (R9). Although one participant said their school used Microsoft Office for schoolwork, every other participant specifically referenced Google products. One benefit of having multiple study participants from the same school is that I was able to triangulate information about technology courses at that school, a STEM-focused magnet. There, every student takes a keyboarding class in $5^{\text {th }}$ grade, and they report daily use of laptops in school, although none described ever being taught any search techniques. "We haven't really talked about using the search bar," reported one $4^{\text {th }}$ grade student already using his laptop to create email and school projects, "but that's kind of simple. Just click the plus and type it in" (R1, 268-270). Reported another student when I asked about their first computer classes at school, "At that point, we knew how to use it" (R2, 398).

A participant who was especially devoted to Google searching described their search process like this: "I just looked on Google. I Googled it" (R9, 229). Seeking 
more details about their research process for a Google Slides presentation on puffer fish, our exchange went like this:

R9: How can different puffer fish live? How, how deadly are they? Do they carry toxins? Stuff like that.

Me: Did you Google it like that, like individual questions?

R9: Individual questions, yes. I'd click enter ... just, question after question, I would click enter, type in the answer from Google, and then on to the next question (229-235).

They went on to say that they especially like to "search on things" using Google because "you have a search ... that is guaranteed to show your answer" (R9, 243). When pressed on this and about whether they ever get to a place where they are not finding a good answer, this participant shook their head emphatically. "I always find the correct answer" (R9, 245), they said, even searching on Google to confirm things they "see around the farm" to "see if it's true or not" (R9, 251-254). This participant struggled most with the library catalog where long search phrases - entered as keyword searches frequently led to "no results." Although absolutely confident in their ability to get the right answer when using Google, they had to work hard to adjust and limit their search terms in order to get results with the catalog and were clearly frustrated at times.

The youngest subset (R1, R8, R9) was also distinctly hesitant to click on links and to use the enter button and were among the most wedded to the idea of a "new tab" to search. Searcher R8, reported to have been part of technology (computers) and media (books) classes as weekly "specials" since Kindergarten, routinely required permission to click on items - hovering endlessly until given approval - and continued to return to the library home page for each search until told about the search bar at the top of each page. 
Participant R9, described above "hitting enter" to get answers from Google, primarily selected options from the drop-down list while using the catalog search bar, never once voluntarily hitting enter after typing a search into the keyword search bar.

Each of these participants was from a different school, and I draw attention to these results because numerous searchers referred to third and fourth grade as a time when they began actually doing project work on the computer (R7, R9, R10) and being instructed in how to use the computer. Searcher R7 specifically referred to third grade as the time when they "first started" using the computer for schoolwork (although they also described activities going back to first grade). At that time, they “didn't know how to use Google Docs” and didn't know that enter “end[ed] a paragraph” (R7, 350, 363-364). These observations cause me to think that an important element of early computer education involves the enter key and how to use it. Children in the midst of those early lessons about enter key function are less fluid in their use and less confident about the result of using it. "I'm not sure what's gonna happen," said third-grade student R8 (238239) after admitting that they were sometimes afraid to click on things. By comparison, seventh grader R10 - who admitted to once accidentally downloading the Chromium virus - described himself as "usually pretty good about knowing" what not to click on, like "a giant 'click-here' button" or "Ooh, free Walmart gift card!" (R10, 435, 437, 440).

Although a few participants had taken outside courses involving coding or block coding - such as in coding summer camps or a Lego Robotics club, etc. - the vast majority reported that their computer-use classwork mainly centered on keyboarding and learning to use Google docs and slides for school projects, often as early as third grade (R9). Many of them reported that they enjoyed learning to type faster and better, but 
none of them could describe a class where they were instructed in how to perform searches online for school projects or how to evaluate search results. One searcher said that they were "given free rein" when searching at school, while another described being sent to a "safe" website to search, where they might be asked to "look up animals on this website that will give you animals" by "typ[ing] it in" or "clicking on the categories" $(\mathrm{R} 5,775,782)$. As has been noted by numerous other researchers, while kidsafe and kid-focused search engines exist, the children themselves will most often reach for adult tools like Google for their personal search needs (Foss et al., 2012; Large et al., 2008; Vanderschantz et al., 2014). These tweens are no different. Searcher R2 notes that in lower school, they used a "kids-based" search engine, which "really didn't give me any answers because it doesn't have as many things on it" (297-298). And when R5 gets done searching for animal categories during school time, he heads for his phone where there's no school surveillance and the searching (Safari) is limitless (R5, 643-650).

One participant was currently taking "computer skills" class where they have discussed hardware and software (R5, 688), and the oldest participant described separate classes beginning in elementary school, with one centering on "online safety" and the other a "computer lab" where they learned how to "navigate the computer" and played games to improve typing skills (R10, 376, 378). This participant described the technology progression for classwork as moving from PowerPoint as optional in elementary school to an expectation in middle school, but then followed up by saying that, even in elementary school, "If you were gonna do a project, it was probably going to be a PowerPoint" $(\mathrm{R} 10,396)$. When I questioned this searcher as to how they found research sources and how they evaluated websites, they responded that they "just use 
Google," are not allowed to use Wikipedia, and have begun creating citations for the websites they use (R10, 409).

\section{Relationship between strategies used and other human influences}

Some participants reported being specifically instructed in using either the library catalog (R5) or the computer (R9) by parents, but even more describe themselves as unable to remember an "earliest memory" of using the computer and having "picked up stuff" from being around parents from the time they were very little: "I guess we just watched her. She wasn't specifically teaching us" (R3, 604). In keeping with their social and emotional development stage as described by Meyers et al. (2009), some exhibited an inclination to go to parents, friends or siblings when experiencing search problems - "I would ask a sibling or a parent, ... 'What's the way you think it might turn up?"' (R3, 592-96) - while others provided some surprisingly Zen-like responses when asked about computer frustration:

- "I just shut it and leave and come back" (R1, 297-98).

- 'I'd probably give up because it's not very necessary [searching at home]. And I could just walk away from it without having any, like, feelings that I was missing something” (R4, 360-363).

- "I take a break. Turn off the computer and just lay down" (R6, 567, 568).

- "I usually just stop for a bit. Do something else and then come back to it. Clear my mind" (R7, 317-319).

In fact, I saw numerous examples of what can go wrong with technology while conducting this study: malfunctioning audio, dropped connections, inability to screen- 
share, and one instance of a "lost mouse." In every case, there was a brief flurry of trying to right the ship and then a desperate call for parental intervention.

More than one participant was pleased by the prospect of learning something new, including R8, who found it "a little bit easy" (307-308, 312-313) to use the catalog after the search bar on each page was pointed out; R9, who discovered the online catalog as a new way to search for books; and R3, who found that unfamiliar search parameters like tags, "actually could be an interesting thing for me to look at" (R3, 160-162). Taken in connection with the fact that most participants referenced learning from adults either directly or through observation, these findings support the research that tweens are eager to learn and developmentally positioned such that adults can and do influence their learning and behavior.

\section{General Observation}

A common behavior among participants was selecting a new tab for each online search. This was a behavior I had not recognized until I was involved in transcribing sessions, when I was able to match up comments like R1's "just click on the plus" with the action being indicated onscreen. Seeing their cursor movements, it became obvious that the "plus" they referred to was the "new tab" symbol. Also clarified was R1's report that they sometimes needed to use a parent's phone to search when "only the tabs that were up were working, and you couldn't ... type in another thing" (185). At the time, I confirmed that he was referring to having so many tabs open that he couldn't fit anymore (R1, 189-190); I did not realize then that he was likely opening a new tab for each search. Returning to the session videos after this, I realized that every participant who had screen-shared prior to navigating to the catalog made sure they had a fresh new tab for 
the session, often first closing a number of other tabs. One searcher was upset because the tiny Zoom screen-share control banner appeared at the top of the screen, making it impossible for them to get a new tab. I started to explain how to type in the available search bar, but they were simultaneously, and hurriedly, closing tabs until the icon appeared to the left of the banner. I was bemused by this at the time. Considered further, however, in light of the data, I began to see this as perhaps the only way they knew to begin a search. And a perfect example of a basic operation that could use intentional instruction.

\section{Specific Difficulties Encountered}

\section{Spelling}

While some searchers took note of and used search assists like the drop-down prior-search offerings or the "Did you mean ...?" query, others never recovered from spelling errors and challenges, and the search was abandoned. Several participants (R4, R6, R7) asked me how to spell a word, while others (R1, R2, R3, R5, R7, R10) quickly adjusted their search terms by accessing or responding to the assists on their own. When directly asked, I variously gave hints or directed the searcher back to the page, depending on how confident I felt they were overall. Searcher R6, who struggled most with spelling, never waited for a response, declaring, "I can’t spell it. Do you want me to search something else?" (102). Later, while searching for books about Muhammad Ali, they began with the spelling "Mohammed Ali," which brought up a book authored by a different Mohammed Ali. They also tried an author-specific search for "Mohammed Ali" and one for "Ali, Mohammed," both of which naturally brought up the same book. In all instances, R6 was so intent on their typing, head lowered to watch the keyboard, that they 
never saw the alternate spelling that showed below the search bar every time they started typing. This was an example where teaching keyboarding skills - creating better, more confident "touch typists" - could be seen to provide a direct benefit to searching, as well.

\section{Comprehension (and Patience)}

Sometimes searchers - even those who were very competent with filters and able to adapt their searches to get results - failed to recognize the information available on the page. For example, when looking for a book on the topic of cartooning, R10 was aware that he wanted something with substance, not "just a graphic novel." Yet despite saying that it might involve the history of cartoons, he repeatedly scrolled past potentially useful material, apparently unable to interpret whether items would be useful. His focus on avoiding cartoon images - and scrolling quickly - may well have caused him to miss the very title he was looking for. Searchers for fiction books "like" Fablehaven or Harry Potter, both of which feature magic and magical creatures, performed keyword searches for magic but never used any filters to try to get closer to a goals, despite being well aware of the filters and their function. In addition, catalog pages for most books - and especially either of these very popular titles - routinely include links to lists containing that book or books like it, either in the comments or the "explore more" section on the right-hand side of the page. Unfortunately, quick peeks and fast scrolling meant none of that information was discovered. This is especially difficult to understand, given that the comments/rating section was highly relied on by this group when deciding between books for research purposes (Search \#2). 


\section{Keyword vs. Google}

Despite its apparent function as an all-purpose search, and the fact that it generally gives the broadest results, when these searchers attempted real Google-style searches - like "mythology books for kids" or "World War 2 allied tanks" - the results were distinctly disappointing. The mythology search (R7) returned one eBook in Spanish, while the tank search (R9) had "no results" and another one for the Civil War (R10) returned only two items. In all cases, the searchers were initially flummoxed. Searcher R7 proceeded to try various adaptations to the search phrase, intentionally broadening and then carefully narrowing it again to get closer to the goal, while R9 made similar attempts, if a bit less focused. When performing the Civil War search, R10 was talking me through his tips for searching, beginning with the broad search and proceeding to use filters to refine the results. Although clearly a bit shocked by getting a list with only two books, R10 carried on describing their process until I asked if they were surprised by the result. Then they laughed, saying, "Yes, a little bit" (R10, 221), and began to question whether they "still [had] one of the filters on" (223). Indeed, when I suggested that they scroll to the top, they saw that they had searched for Civil War as an author and were quickly able to rerun the search.

For these searchers - and many others, no doubt - using a keyword search like a Google search works often enough that they don't question why or how it might be different. By relying on Google algorithms and function as the predominant framework for up and coming generations of searchers, however, we shortchange them on their ability to truly become the most competent information seekers they can be. Even opening that dialogue, questioning how these tools work, has value to these growing 
minds, while waiting raises generations of information seekers who think Google actually equals searching, for every purpose. Likewise, they will struggle with any non-Google search process by failing to understand the distinctions - and potential benefits - of any other way of searching. Surely, being labeled a digital native should not mean one is thrown into Google Sea with no support, not mean falling back on the belief that because you always get something, it must be a good something. These kids may be called digital natives because they were born into a world of digital products, but they will never be able to truly reach their potential if they are searching blindly and always expecting a Google response. Large et al. (2008) have noted that "practice alone does not make perfect" (p. 137) when it comes to information seeking. Likewise, repeated exposure to constantly changing cause and effect leads to confused expectations and must surely slow down learning and forward progress.

From this study, I find no evidence that any education is provided that teaches children how to search. I had assumed (perhaps mistakenly) that this would fall in the realm of learning to use the computer, since that is one of the things students say they do during school: research things on their laptops. Every tween in this study reported that they do research for writing essays and creating projects, but none could describe being instructed in how that should be done, either by their regular teacher, a librarian, or a technology specialist. Indeed, many believed they already knew all about it by the time they were halfway through elementary school. Watching them formulate searches and try to fit Google search methods into a library catalog tells me there is work to be done to bridge that gap. 


\section{Catalog Function}

Despite the fact that I work with this catalog constantly during my job at the library and at home, this study highlighted a number of flaws or difficulties in the way it functions, as well as providing me an opportunity to find new functions while the kids completed their tasks. Some of the issues listed below are well known to library staff (e.g., list functionality), while others are simply inherent in any endeavor where human error is possible (e.g., cataloging errors), but they can all impact users ability to search effectively and to learn from prior searches. And since this population is largely learning as they go, these issues matter.

\section{Difficulties}

- Cataloging errors that cause filters to be partially ineffective.

○ Genre/form slippage, i.e., the graphic novel that continues to appear on a results list filtered only to "books."

- For some titles, only eBooks format tagged with series designation; extremely frustrating to a population dedicated to following their favorite series.

- Images, descriptions, and other information missing or abbreviated, which frustrates book engagement and selection.

- Lists are difficult to access and sort through.

- Lists that do appear on item records appear inconsistently, sometimes under "Explore More" blocks or perhaps attached only to comments of the first book in a series. 
- Among catalog functions that consistently went unused were "Advanced Search" and the option to "Browse by Call Number," which allows for limited exploration of items that would be located on the shelves before and after the selected item.

One unintended search function that impacted study participants positively was the appearance of new books at the top of the list. This was a benefit to searchers who searched for a series or author using the "keyword" search, although I learned later that searching for a series by name, using the "series" limiter caused new books to drop out of sight by pushing them to their proper place on the list: the bottom. Because following a favorite author or series was a favorite way for these participants to find new books they wanted to read, this was one instance when an imprecise (albeit common) use of the tool resulted in a benefit to searchers. 


\section{Conclusion}

Similar to the goal expressed by Foss et al. (2012) in their study of children's search roles at home, this study sought to "arrive at a broader understanding of the whole searcher by observing affect, uncovering searching rules, and noting the people [and/or digital literacy training] who influence search" (p. 558), although, in this instance, through close observation of individual children using a particular search tool. The children involved in this study engaged with the tasks and the topic of searching with great diligence and vigor. Although it is never a natural activity to "think aloud" one's actions, the participants tried to do this strange thing and were patient with all my questions and with my occasional requests to repeat tasks. I believe the data collected answers the research questions. In fact, I found the unfiltered nature of the children's responses to be highly insightful.

Based on the information from this group of searchers, their main means of learning how to search online for information of any sort is experience. They start young and build their own knowledge base from the time they spend on the computer. They're not obsessed with data, nor do they spend all their time planning online games with their friends, and perhaps this is one effect of being born a so-called digital native: the ability to take technology for granted. But they are immersed in technology, using it - expected by their teachers to use it - daily to complete school tasks. For these tasks, they begin training early, by the middle of elementary school, to create and share documents online 
and to report on projects through slide shows. They are apt pupils, learning at school and at home, from everything and everyone around them.

Teachers and librarians, parents, and friends all impact what they learn and how they search, but they also learn in less formal ways, through watching and experimenting on their own. Where formal classes are almost entirely geared toward office and presentation skills - email communication, keyboarding, creating and submitting documents, and slide presentations - Google is always there "guaranteeing" an answer and making itself the perfect search enabler. With Google it is easy to get results, even if you hardly try. There is so much there! But as we know, not all results are created equal, and learning to evaluate those results can be a difficult, and not entirely intuitive, process.

The tweens I spoke with all described doing online research in the course of completing school assignments, but none of them described any teacher input into how that research should be carried out. They are instructed to watch for stranger-danger, to avoid clicking on suspicious links, but what about instilling a sense of what they should click on or how they should effectively deal with their search results without limiting themselves to the first five items? Based on the words of the children in this study, and the fact that most of them use Google products at school and at home, it might be fair to say that Google is teaching them how to search.

Library and Information Science professionals - as well as all people interested in understanding how the next generation fully realizes the potential of technological innovations in the world of information retrieval - should be interested in these results. Although this was a small study exploring connections between children's use of library search tools and their other experiences with technology, the results point the way toward 
making a difference in improving that experience for all children. They also provide insight into deeper consideration of our understanding of children as digital natives by providing relevant connections that could help guide curriculum changes and model new search technology on the path to true digital fluency by beginning to understand how children use existing tools in one of the most basic search exercises: finding a book at the library. Google makes searching easy. Children in elementary school are already using it and quickly begin to believe it is the answer to all their search needs, with many believing they have mastered searching by the time they are nine years old! Right now, though, tweens are still open to guidance and information from the adults around them, and we should do everything we can to guide and inform them about the power they have, not only to find answers but to find the best answers. One way we do this is by affirmatively instructing them in how to search and how to evaluate the results of their searches beyond Google. 


\section{References}

Allen, M. (2017). Thematic Analysis. In The SAGE encyclopedia of communication research methods. 2455 Teller Road, Thousand Oaks California 91320 : SAGE Publications, Inc. doi:10.4135/9781483381411.n624

Beheshti, J., Cole, C., Abuhimed, D., \& Lamoureux, I. (2015). Tracking middle school students' information behavior via Kuhlthau's ISP Model:Temporality. Journal of the Association for Information Science and Technology, 66(5), 943-960. doi:10.1002/asi.23230

Bilal, D. (2005). Children's information seeking and the design of digital interfaces in the affective paradigm. Library trends, 54(2), 197-208. doi:10.1353/lib.2006.0013

Coleman, J. (2007). Browsing 101: How Do You Find a Good Book?. Library Media Connection.

Crow, S. R. (2009). Relationships that Foster Intrinsic Motivation for Information Seeking. School Libraries Worldwide, 15(2), 91-112.

Crow, S. R. (2013). Researching Stuff is the Best! Teacher Librarian, 41(1), 34-41.

Deci, E. L., \& Ryan, R. M. (2000). The "What" and "Why" of Goal Pursuits: Human Needs and the Self-Determination of Behavior. Psychological inquiry, 11(4), 227-268. doi:10.1207/S15327965PLI1104_01

Foss, E., Druin, A., Brewer, R., Lo, P., Sanchez, L., Golub, E., \& Hutchinson, H. (2012). Children's search roles at home: Implications for designers, researchers, 
educators, and parents. Journal of the American Society for Information Science and Technology, 63(3), 558-573. doi:10.1002/asi.21700

Kuhlthau, C. C. (2009). Information search process (ISP) model. In M. J. Bates \& M. N. Maack (eds.), Encyclopedia of library and information sciences, third edition (pp. 2586-2591). CRC Press. doi:10.1081/E-ELIS3-120043229

Kuhlthau, C. C., Heinstrom, J., \& Todd, R. J. (2008). The "information search process" revisited: is the model still useful? Information Research, 13(4), 355.

Large, A., Nesset, V., \& Beheshti, J. (2008). Children as information seekers: what researchers tell us. New Review of Children's Literature and Librarianship, 14(2), 121-140. doi:10.1080/13614540902812631

Lockyer, S. (2008). The SAGE Encyclopedia of Qualitative Research Methods. (L. M. Given, ed.). Thousand Oaks: SAGE Publications Inc. doi:10.4135/9781412963909

Madden, A. D., Ford, N. J., Miller, D., \& Levy, P. (2006). Children's use of the internet for information-seeking. Journal of Documentation, 62(6), 744-761. doi:10.1108/00220410610714958

Merga, M. K., \& Roni, S. M. (2017). Choosing strategies of children and the impact of age and gender on library use: insights for librarians. Journal of library administration, 57(6), 607-630. doi:10.1080/01930826.2017.1340774

Meyers, E., Fisher, K., \& Marcoux, E. (2009). Making sense of an information world: the everyday-life information behavior of preteens. The Library quarterly, 79(3), 301-341. doi:10.1086/599125 
Montgomery, B. (2014). A Case for Browsing: An Empowering Research Strategy for Elementary Learner. Knowledge Quest, 43(2), E5-E9.

Moore, P. (1995). Information problem solving: A wider view of library skills. Contemporary educational psychology, 20(1), 1-31. doi:10.1006/ceps.1995.1001

Raqi, S. A., \& Zainab, A. N. (2008). Observing Strategies Used by Children When Selecting Books to Browse, Read, or Borrow. Journal of Educational Media \& Library Sciences, 45(4), 485-503.

Shenton, A. K., \& Dixon, P. (2004). How Do Youngsters Use Public Libraries to Find Non-Fiction Books? The Results of a Recent Research Project. Public Library Quarterly, 23(3-4), 77-98. doi:10.1300/J118v23n03_12

Taylor, J. B., Hora, A., \& Krueger, K. S. (2019). Self-selecting books in a children's fiction collection arranged by genre. Journal of Librarianship and Information Science, 51(3), 852-865. doi:10.1177/0961000617743088

Vanderschantz, N., \& Hinze, A. (2019). Computer what"s your favourite colour?’ children"s information-seeking strategies in the classroom. Proceedings of the Association for Information Science and Technology, 56(1), 265-275. doi:10.1002/pra2.21

Vanderschantz, N., Hinze, A., \& Cunningham, S. J. (2014). Sometimes the internet reads the question wrong“: Children”s search strategies \& difficulties. Proceedings of the American Society for Information Science and Technology, 51(1), 1-10. doi:10.1002/meet.2014.14505101053 


\section{Appendix A. No Pressure Statement}

[To be read aloud at the beginning of every think-aloud session and interview]

I want to thank you (child's name) for helping me with my research about how kids use the online library catalog. In fact, I wouldn't be able to do this study if not for kids like you, who have agreed to help. But I also want you to know that you do not have to feel any pressure about this because there are no right or wrong answers you could give and no wrong choices you could make. Some specific things to keep in mind:

1. If I ask you a question - like "why" you did something or "what did you just say?" - it does not mean that you said anything wrong or bad; I just need to understand.

2. If you don't know the answer to a question I ask, that's okay, too.

3. If you feel uncomfortable [or like you need your parent to join us], just tell me and we can stop [and/or get your parent].

4. If you want to stop, you can always tell me you need to stop; I will not be angry or upset with you.

5. If you need to ask me a question, you can ask me a question. (It might help me do better with the next person I interview!)

And remember ... There are no right or wrong answers; just tell me what you think, and that is the best answer. 


\section{Appendix B. Guided Interview Outline}

[Each interview session to begin with the reading of Appendix A. "No

\section{Pressure" Statement]}

The following is a list of questions/areas to explore during retrospective interviews, to be held with each participating child, so long as they continue to give consent. I do not intend to specifically ask every question, but these are the subject areas I intend to cover.

- Background data (age, grade, school, etc.)

- Experience with and feelings about using search tools, in general

Do you use the computer to search at home? For what reason(s)?

- Do you use the computer to search at school? For what reasons(s)?

○ Do you use a smartphone to search? When and for what reason(s)?

- Feelings about this particular search tool or process

- Have you used this library search tool (BiblioCommons) before? How often (in terms of regularity) and why? [capture all uses]

○ Have you used a different catalog tool at a different library? Where? How often? [capture all uses]

- Technology courses or training they may have undergone

- Have you taken any classes about using the computer or doing research on a computer?

- Where?

- Who taught it? 
- Why did you take it?

- How long did it last?

- Did you enjoy it?

- Do you use the computers at school?

- Does anyone talk to you about the using the computers?

- Where do you use the computer at school? [where are they physically located - list all]

- How often do you use them?

- Why do you use them?

- What if you have a question or get stuck on something when using the computer? Who do you get help from?

- Other individuals/situations affecting search behavior

- Are there people who help you use the computer when you are not at school?

○ Do you use the computer by yourself? Or are other people in the room?

- Do you play games with friends on the computer? Online or in person?

- Is there a friend you go to if you have a computer question at home?

Is there an adult you go to if you have a computer question at home?

○ At home, do you have a computer in your room?

- If you use a computer, where is the computer that you use located?

- If you use a computer, do you have rules at home about using the computer? 
- What if you have a computer question while you are at home? Who do you ask?

Thank you! 